\title{
MICROBIAL TRANSFORMATION OF DAUNOMYCINONE BY STREPTOMYCES AUREOFACIENS B-96
}

\author{
Jaroslava Karnetová, Jiḱí MatěJư, Petr Sedmera, JindRích Vokoun \\ and ZDENKO VANĚK \\ Institute of Microbiology, Czechoslovak Academy of Sciences, \\ Prague, Budějovická 1083, Czechoslovakia
}

(Received for publication July 12, 1976)

\begin{abstract}
Daunomycinone, aglycone of the anthracycline antibiotic daunomycin, was transformed by a washed mycelia of Streptomyces aureofaciens B-96 in a buffer solution containing sucrose; the obtained product, dihydrodaunomycinone (9-(1-hydroxyethyl)-7,8,9,10-tetrahydro-6,7,9,11tetrahydroxy-4-methoxy-5,12-naphthacenequinone), was identified by measuring basic physicochemical characteristics (IR, UV and visible spectra, mass spectra and NMR, optical rotation and m.p.).
\end{abstract}

The mutant strain, Streptomyces aureofaciens B-96 producing the glycoside aureovocin, has the ability to glucosidize certain hydroxyderivatives of anthraquinones ${ }^{9}{ }^{10}$. In the present communication this strain was used to investigate transformation of daunomycinone (Fig. 1), aglycone of the antitumor antibiotic daunomycin.

Fig. 1. Daunomycinone.

\section{Material and Methods}

Spectra

Ultraviolet and visible spectra were measured in a Cary $118 \mathrm{C}$ spectrophotometer (methanol), infrared spectra ( $\mathrm{KBr}$ tablets) were measured in a Unicam SP-200 spectrophotometer,<smiles>COc1cccc2c1C(=O)c1c(O)c3c(c(O)c1C2=O)CC(O)(C(C)=O)CC3O</smiles>
mass spectra with a Varian MAT-311 (energy of ionizing electrons $70 \mathrm{eV}$, current of ionizing electrons $1 \mathrm{~mA}$, temperature of ion source $200^{\circ} \mathrm{C}$, temperature of direct inlet system $170^{\circ} \mathrm{C}$, high resolution measurement was performed with an error less than $5 \mathrm{ppm}$ ) and metastable transformations were studied using the DADI technique ${ }^{11)}$. NMR spectra were measured in a Varian HA-100 $(100 \mathrm{MHz})$ spectrometer in a mixture of $\mathrm{CDCl}_{3}+\mathrm{d}_{6}$-DMSO, TMS serving as internal standard. Optical rotations were determined in a Jasco-5 spectropolarimeter.

Strain and Cultivation

The strain, Streptomyces aureofaciens B-964), was maintained on agar slants ${ }^{\text {(). }}$. Spores were transferred to the inoculation medium containing soya-bean meal ${ }^{7}$.

The flasks with the fermentation medium ${ }^{8}$ ) were inoculated with a 16 -hour inoculum $(5 \%)$. After a 20-hour cultivation, the mycelia of the second vegetative generation were separated by centrifugation $\left(2^{\circ} \mathrm{C}, 10\right.$ minutes, $\left.1,000 \mathrm{~g}\right)$, washed with water, excess water was removed by centrifugation $\left(2^{\circ} \mathrm{C}, 10 \mathrm{~min}\right.$ utes, $10,000 \mathrm{~g}$ ) and the mycelia were maintained at $-20^{\circ} \mathrm{C}$.

The strain, $S$. aureofaciens B-96, was cultivated on a reciprocal shaker $(1.6 \mathrm{~Hz}$, amplitude $10 \mathrm{~cm})$ at $28^{\circ} \mathrm{C}$.

Hydrolysis of Daunomycin

Daunomycin (Medexport, $100 \mathrm{mg}$ ) was hydrolyzed with $0.35 \mathrm{~N} \mathrm{HCl}\left(250 \mathrm{ml}, 1.5\right.$ hours, $\left.100^{\circ} \mathrm{C}\right)$. After neutralization with ammonia, the reaction mixture was extracted with chloroform. The solvent was removed by distillation and the residue was chromatographed on a silica-gel column $(100 \mathrm{~g}$, Kieselgel 60 , particle size $0.063 \sim 0.200 \mathrm{~mm} / 70 \sim 230$ mesh ASTM/Merck) and eluted with a solvent series of 
benzene and chloroform (7:3 1:1).

Microbial Transformation and Isolation of the Product

The mycelia were incubated with daunomycinone in $0.2 \mathrm{M}$ Tris- $\mathrm{HCl}$ buffer $\mathrm{pH} 7.5$ (50 ml per flask) with $4 \%$ sucrose; $100 \mu$ l daunomycinone in dimethylformamide $(25 \mathrm{mg} / \mathrm{ml})$ was added to the flasks. After the incubation, the mycelia were separated by centrifugation and extracted with methanol. The fermentation liquid was extracted with ethylacetate. The dried extract was evaporated under reduced pressure and purified by chromatography on a silica-gel column $(80 \mathrm{~g})$. The column was eluted with a series of solvents benzene, benzene - chloroform $(9: 1 \sim 1: 1)$, chloroform, chloroform - methanol (9.5: $0.5 \sim 9: 2) \quad$ The final purification of the product was carried out by repeated thin-layer chromatography (Silufol, Kavalier Czechoslovakia) in the solvent mixture chloroform - methanol - water(9: 1.5: $0.1)$.

\section{Results and Discussion}

The microbial transformation of daunomycinone by the strain $S$. aureofaciens B-96 gave rise to a red compound $\left(45 \mathrm{mg}\right.$ ) forming needles with m.p. $183 \sim 185^{\circ} \mathrm{C}$ (hexane - chloroform) and an optical rotation of $[\alpha]_{\mathrm{D}}^{20} 97^{\circ}\left(c 0.05, \mathrm{CHCl}_{3}\right)$. Ultraviolet and visible spectra are identical with those of daunomycinone. In the mass spectrum (Fig. 2) this compound has a molecular ion $\mathrm{m} / \mathrm{e} 400$ corresponding to $\mathrm{C}_{21} \mathrm{H}_{20} \mathrm{O}_{8}$, a molecule having two additional hydrogen atoms with respect to daunomycinone. Comparison of the fragmentation schemes of both compounds indicates that the base peak of the spectrum originates in both cases by the loss of two water molecules. A difference is observed in splitting of the $\mathrm{M}--\mathrm{H}_{2} \mathrm{O}$ ion; in daunomycinone the side chain is lost due to splitting of $\mathrm{C}_{2} \mathrm{H}_{3} \mathrm{O}$ (Bullock et al. ${ }^{5}$ ), whereas in the case referred to here, $\mathrm{C}_{2} \mathrm{H}_{4} \mathrm{O}$ is eliminated (Fig. 3). The infrared spectrum reveals bands at 1565 and $1605 \mathrm{~cm}^{-1}$ that belong to the quinone carbonyls and are identical with those in the spectrum of daunomycinone; however, the band at $1700 \mathrm{~cm}^{-1}$ of the aliphatic carbonyl is missing.

The proton magnetic resonance spectrum contains, similarly to daunomycinone, the methoxy group signals $(\delta 4,06)$, further signals of the $\mathrm{ABC}$ system of three vicinal aromatic protons $(\delta 7.38,7.44$ and 7.95 $\left.\left(\mathrm{J}_{\mathrm{AB}}=8 \mathrm{~Hz}, \mathrm{~J}_{\mathrm{AC}}=1.5 \mathrm{~Hz}, \mathrm{~J}_{\mathrm{BC}}=8 \mathrm{~Hz}\right)\right)$, signals of the ABX system of the grouping $\mathrm{O}-\mathrm{CH}-\mathrm{CH}_{2}(\delta 5.25$, 2.43 and $1.76\left(\mathrm{~J}_{A X}=5 \mathrm{~Hz}, \mathrm{~J}_{B X}=1.5 \mathrm{~Hz}, \mathrm{~J}_{A B}=15 \mathrm{~Hz}\right)$ ) and the $A B$ system of the isolated methylene group $\left(\delta 3.13\right.$ and $\left.2.61\left(\mathrm{~J}_{\mathrm{AB}}=18.5 \mathrm{~Hz}\right)\right)$. However, instead of the methylene group singlet a secondary methyl doublet $(\mathrm{J}=6.2 \mathrm{~Hz}),(\delta 1.29)$ is present. It is coupled (as verified by a double resonance experiment) to the methine proton ( $\delta 3.71$ (quadruplet $\mathrm{J}=6.2 \mathrm{~Hz}$ )). The latter two signals belong to the moiety $\mathrm{CH}_{3}-\mathrm{CH}-$ bound to a quarternary carbon.

Fig. 2. Mass spectra of dihydrodaunomycinone.

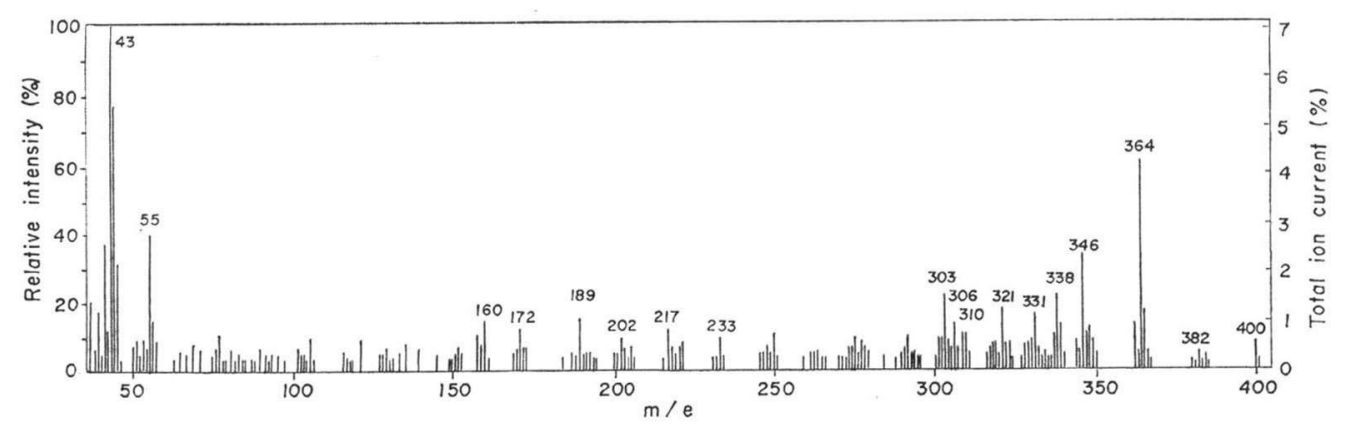


Fig. 3. Fragmentation scheme of dihydrodaunomycinone.

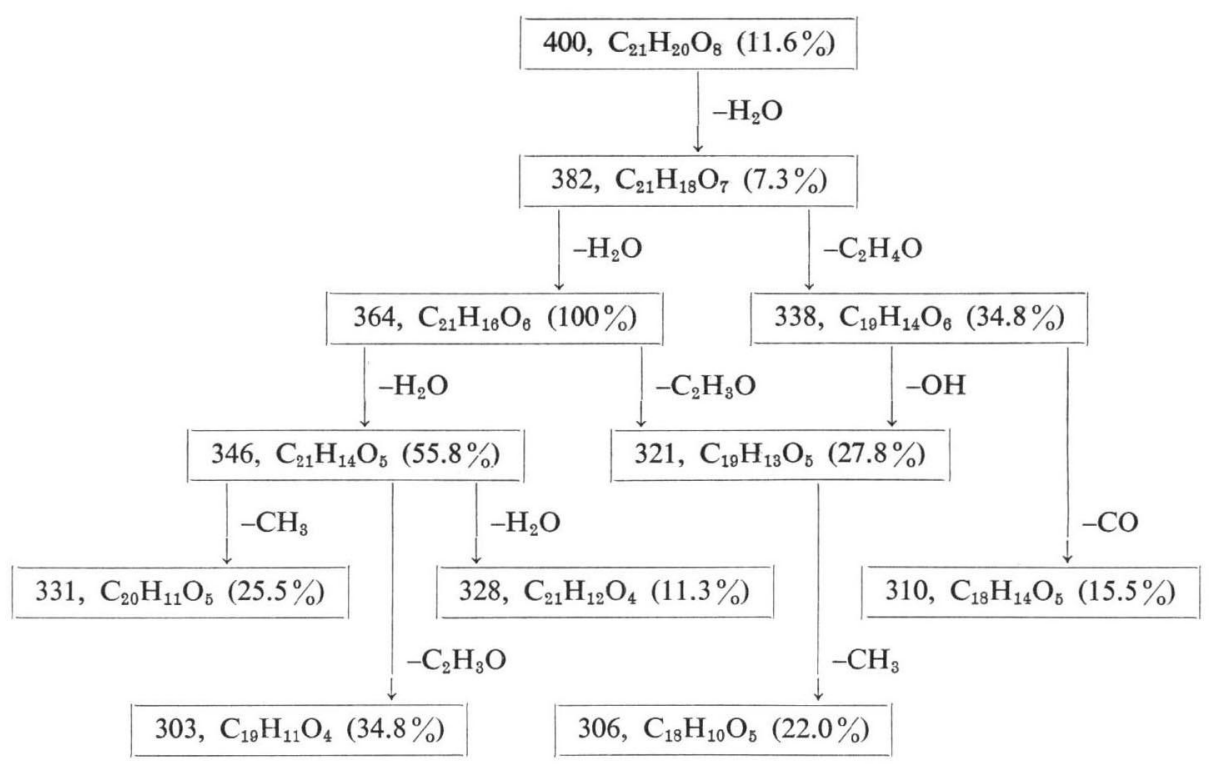

It follows from all the data presented that the transformation product is dihydrodaunomycinone (9-(1-hydroxyethyl)-7,8,9,10-tetrahydro-6,7,9,11-tetrahydroxy-4-methoxy-5,12-naphthacenequinone(Fig. 4) differing from daunomycinone by a 1-hydroxyethyl group at $\mathrm{C}_{9}$ instead of the acetyl group.

The formation of the same metabolic product by reduction of the carbonyl group in the side chain of daunomycinone was described in mice, rats, and hamsters ${ }^{13)}$. An enzyme catalysing the reduction of daunomycin was isolated from mammalian tissue homogenates ${ }^{2,8)}$. The reaction is NADPH-dependent $t^{1,3,5}$.

Fig. 4. Dihydrodaunomycinone.

It may be assumed on the basis of our results that a similar enzymic system reducing daunomycinone is present also in the strain, Streptomyces aureofaciens B-96.

\section{References}

1) Asbell, M. A.; E. Schwartzbach, F. J. Bullock \& D. W. Yesair: Daunomycin and adriamycin metabolism via reductive glycosidic cleavage. J. Pharmacol. Exp. Ther. 182: 63 69, 1972

2) Bachur, N. R. \& D. H. Huffman: Daunorubicin metabolism. Estimation of daunorubicin reductase. Brit. J. Pharmacol. 43: 828 833, 1971

3) BACHUR, N. R.: Daunorubicinol, a major metabolite of daunorubicin: Isolation from human urine and enzymatic reactions. J. Pharmacol. Exp. Ther. 177: 573 578, 1971

4) Blumauerová, M.; M. Mraček, J. VondráčKovÁ, M. Podojil, Z. HošŤálek \& Z. VaněK: Regulation of biosynthesis of secondary metabolites. IX. The biosynthetic activity of blocked mutants of Streptomyces aureofaciens. Folia Microbiol. 14: 215 225, 1969

5) Bullock, F. J.; R. J. BRuni \& M. A. Asbell: Identification of new metabolites of daunomycin and adriamycin. J. Pharmacol. Exp. Ther. 182: 70 76, 1972

6) Felsted, R. L.; M. Gee \& N. R. Bachur: Rat liver daunorubicin reductase. An aldo-keto reductase. J. Biol. Chem. 249: 3672 3679, 1974

7) Herold, M.; E. BěLík \& J. DoskočIL: Biosynthesis of chlortetracycline without maintenance of aseptic 
conditions. Giorn. Microbiol. 2: 302 341, 1956

8) HošŤÁLEK, Z.: Relationship between the carbohydrate metabolism of $S$. aureofaciens and the biosynthesis of chlortetracycline. III. The effect of benzylthiocyanate on carbohydrate metabolism of S. aureofaciens. Folia Microbiol. 9: 96 102, 1964

9) Hovorková, N.; J. Cudlín, J. MatěJŮ, M. Blumauerová \& Z. VaněK: Microbial glucosidation of alizarin and anthraflavin. Coll. Czech. Chem. Commun. 39: 662 667, 1974

10) Matě̀ứ, J.; J. Cudlín, N. Hovorková, M. Blumauerová \& Z. VanĚK: Microbial glucosidation of dihydroxyanthraquinones. General properties of the glucosidation system. Folia Microbiol. 19:307 316,1974

11) Mauer, K. H.; C. Brunee, G. Kappus, K. Habfast, U. Schröder \& P. Schulze: Direct analyses of daughter ions. 19th Conference on Mass Spectrometry, Atlanta, Paper K-9, 1971

12) Vokoun, J.; Z. Vaněk, M. Podojil, M. Blumauerová, M. Vondráček \& A. Benda: Czechoslov. Pat. No. 153,772 (PV 8211-70), 1974

13) Yesair, D. W.; E. Schwartzbach, D. Shuck, E. P. Denine \& M. A. Asbell: Comparative pharmacokinetics of daunomycin and adriamycin in several animal species. Cancer Res. 32: 1177 1183, 1972 